\title{
A pessoa com deficiência intelectual e as concepções de professores de educação especial
}

\author{
The person with intellectual disability and the conceptions of special education \\ teachers
}

\section{La persona con discapacidad intelectual y las concepciones de profesores de educación especial}

\author{
Andressa Caetano Mafezoni ${ }^{2}$ \\ Caroline Simon ${ }^{3}$
}

\begin{abstract}
Resumo: Objetiva-se discutir as concepções de professores de educação especial de um município do Espírito Santo (Brasil) sobre a pessoa com deficiência intelectual. Trata-se de uma pesquisa de natureza qualitativa e de caráter exploratório, empregando-se a aplicação de cento e cinquenta e um questionários abertos como técnica de coleta de dados. Como discussões e considerações, constatou-se, por um lado, que os professores de educação especial ainda concebem a pessoa com deficiência intelectual numa perspectiva de limitação de ordem biológica em relação às possibilidades de desenvolvimento e aprendizagem. Essas concepções estigmatizantes contribuem para a construção de uma postura pedagógica que compreende a pessoa com deficiência intelectual como um indivíduo delimitado pela não aprendizagem, sobre o qual há pouca ou não há expectativa. Por outro lado, observa-se o surgimento de uma tendência que busca superar essa perspectiva em direção a uma concepção que aposta nas potencialidades da pessoa com deficiência intelectual.
\end{abstract}

Palavras-chave: Educação especial. Deficiência intelectual. Professores especialistas.

Abstract: The objective of this study is to discuss the conceptions of special education teachers of an Espirito Santo (Brazil) municipality about a person with an intellectual disability. It is a qualitative and exploratory research study, with the application of one hundred and fifty-one open questionnaires as a data collection technique. As discussions and considerations, it was found that teachers of special education still perceive the person with intellectual disability from a perspective of biological limitation regarding the possibilities of development and learning. These stigmatizing conceptions contribute to the construction of a pedagogical posture that includes the person with intellectual disability as an individual defined by the inability to learn, over which there is little or no expectation. On the other hand, it is observed the emergence of a tendency that tries to overcome this perspective towards a conception that bets on the potentialities of the person with intellectual deficiency.

Keywords: Special education. Intellectual disability. Specialist teachers.

Resumen: El objetivo es discutir las concepciones de los profesores de educación especial en una ciudade de Espirito Santo (Brasil) sobre las personas con discapacidad intelectual. Se trata de una investigación de naturaleza cualitativa y de carácter exploratorio, con la aplicación de ciento cincuenta y un cuestionarios abiertos como técnica de recolección de datos. Como discusiones y consideraciones, se constató que los profesores de educación especial todavía conciben a la persona con discapacidad intelectual en una perspectiva de limitación de orden biológico en relación con las posibilidades de desarrollo y aprendizaje. Estas concepciones estigmatizantes contribuyen a la construcción de una postura pedagógica que comprende a la persona con discapacidad intelectual como un individuo delimitado por el no aprendizaje, sobre el cual hay poca o ninguna expectativa. Por otro lado, se observa el surgimiento de una tendencia que busca superar esa

\footnotetext{
${ }^{1}$ Submetido em: 14 jun. 2019 - Aceito em: 19 ago. 2019 - Publicado em: 29 jul. 2020

${ }^{2}$ Universidade Federal do Espírito Santo (UFES) - E-mail: andressamafezoni@ yahoo.com.br

${ }^{3}$ Universidade Federal do Espírito Santo (UFES) - E-mail: carolinesimon.edu @ gmail.com
} 
perspectiva en dirección a una concepción que apuesta por las potencialidades de la persona con discapacidad intelectual.

Palabras clave: Educación especial. Discapacidad intelectual. Profesores especialistas.

\section{Introdução}

Ao longo das últimas décadas, a Educação Inclusiva tem se desenhado numa perspectiva do direito de todos os alunos à educação. Esse imperativo inclusivo vem se delineando internacionalmente desde a década de 1990, tendo como marcos de destaque a Declaração Mundial sobre Educação para Todos (1990) e a Declaração de Salamanca (1994); em 2006, ocorreu a Convenção dos Direitos das Pessoas com Deficiência da Organização das Nações Unidas (ONU). Adepto desses movimentos, o Brasil tem elaborado uma legislação alinhada a esse paradigma emergente, o que resultou, por exemplo, na criação da Lei de Diretrizes e Bases da Educação Nacional (LDBEN) nº 9394, de 20 de novembro de 1996; da Política Nacional de Educação Especial na Perspectiva da Educação Inclusiva, em 2008, e de outros documentos subsidiários.

Por meio desse movimento de implantação de políticas públicas de Educação Inclusiva, a formação de professores tem sido impactada pela diversidade de alunos na escola, como uma marca que a universalização da educação trouxe para o âmbito escolar, na medida em que as orientações legais nos níveis internacional e nacional têm apresentado o desafio de desenvolvermos uma educação para todos e para cada um em particular. Conforme Melo e Mafezoni (2019), entendemos o direito à educação como uma premissa básica de acesso, permanência e direito à aprendizagem. É necessário que os profissionais da educação, apoiados pelos respectivos sistemas de ensino, proponham reflexões e mudanças que configurem a prática inclusiva construída e concreta em sua proposta pedagógica. No entanto,

[...] tais mudanças no campo da política de educação especial, desde seu início, provocaram fortes tensões que ainda se mantêm entre aqueles que apontam para a necessidade de uma mudança radical no modo de escolarizar todos os alunos do Público Alvo da Educação Especial nas classes regulares de escolas comuns [...] (MENDES, 2019, p. 6).

Em relação à formação de professores, é importante pensar que o processo de formação inicial e continuada para uma perspectiva de inclusão escolar impactam a cultura escolar e o desenvolvimento profissional. Nesse sentido, há uma relação entre o que se aprende na formação inicial e continuada e o que se faz na prática pedagógica, na tomada de decisões e suas consequências. É preciso refletir que essa formação, somada ao desenvolvimento das políticas públicas em educação, precisam promover mais igualdade tanto em acesso quanto em permanência, sob a égide do direito de aprender de alunos com deficiência intelectual, que têm sido historicamente excluídos do processo de escolarização.

Desse modo, considerando a imprecisão conceitual que ainda se acerca da noção de deficiência intelectual, o presente estudo tem como objetivo compreender como os professores de educação especial de um município da Região Metropolitana da Grande 
Vitória (RMGV), no estado do Espírito Santo (ES), concebem a pessoa com deficiência intelectual. Partimos do pressuposto de que o entendimento do conceito de deficiência intelectual e, consequentemente, da pessoa que vive essa condição, influencia a maneira como o professor orientará sua atuação com o aluno e, possivelmente, como ressignificará a implementação de políticas públicas e orientações voltadas ao atendimento do público-alvo da educação especial. Em âmbito escolar, o desconhecimento ou a compreensão equivocada desse conceito acarreta a elaboração de um planejamento pedagógico que desconsidera as possibilidades de trabalho no processo de ensino e aprendizagem do aluno, prejudicando sobremaneira seu desenvolvimento.

\section{Método}

Esse texto faz parte de um projeto maior de pesquisa que tem por objetivo aprofundar as discussões acerca do conceito de deficiência intelectual a partir do de inteligência. $\mathrm{O}$ método investigativo utilizado nessa pesquisa é de natureza qualitativa e de caráter exploratório. Essa perspectiva possibilita, no entendimento de Moreira e Caleffe (2008), que as pesquisas de caráter exploratório sejam desenvolvidas com o objetivo de proporcionar uma visão geral, de tipo aproximativo, acerca de determinado fenômeno.

Diante disso, utilizamos como técnica de coleta de dados, a aplicação de 250 questionários, em um dia de formação continuada para professores de educação especial, de um município da RMGV/ES, obtendo o retorno de 151 questionários. Esclarecemos que, dos 151 professores de educação especial, 139 são formados no curso de Pedagogia e 12 professores são formados em outras licenciaturas (quatro em Letras - Língua Portuguesa, três em Educação Física, dois em Ciências Biológicas, um em Música e dois formados em Magistério). Salientamos que 146 respondentes possuem curso de pós-graduação lato sensu em alguma área educacional, principalmente em Educação Especial/Inclusiva, especialização que, inclusive, habilita aqueles que não são formados em Pedagogia a ocupar o cargo de professor de educação especial.

As questões contidas no questionário foram do tipo abertas, em número de dez, entre as quais perguntamos: qual é a sua concepção de pessoa com deficiência intelectual? Após a leitura e a análise das respostas obtidas por meio dos questionários, construímos cinco categorias de análise: i) a pessoa com deficiência intelectual é alguém com dificuldade de aprendizagem e/ou de raciocínio (38 respostas); ii) a pessoa com deficiência intelectual é alguém que precisa ser cuidada, precisa do apoio e/ou atenção do outro (31 respostas); iii) pessoa com deficiência intelectual é alguém que possui limitações e/ou incapacidades com seu próprio tempo em formas diferentes de aprender (30 respostas); iv) pessoa com deficiência intelectual como alguém que possui seu próprio tempo e tem formas diferentes de aprender; e, v) a pessoa com deficiência intelectual é alguém com potencialidades e/ou é um sujeito com direitos e deveres (29 respostas).

Estudamos as respostas por meio da análise de conteúdo, com base em Bardin (1988), ou seja, decompomos, identificamos e analisamos grupos formados por representações, 
categorizando os significados e tornando possível a compreensão do assunto estudado. Segundo Bardin (1988), tudo que é dito ou escrito pode ser submetido a uma análise do conteúdo. De acordo com Laville e Dionne (1999, p. 214-215), “[...] a análise do conteúdo consiste em demonstrar a estrutura e os elementos desse conteúdo para esclarecer suas diferentes características e extrair sua significação [...]". Pode-se aplicar uma grande diversidade de objetos de investigação: atitudes, valores, representações, mentalidades, ideologias etc. Reforçamos que esse não é um método rígido, mas tem por base a reconstrução do sentido de um conteúdo.

\title{
O imaginário social, o estigma, a normalidade e a patologia
}

Para nos auxiliar na discussão a respeito das concepções de professores sobre a pessoa com deficiência intelectual, nos baseamos em Bronislaw Baczko, que discorre sobre o imaginário social; em Erving Goffman, que nos auxilia com sua análise acerca da concepção de estigma, e Georges Canguilhem, que oferece contribuições sobre a dicotomia entre a normalidade e a patologia. Dessa forma, Baczko (1999) explica que o imaginário social corresponde a um mecanismo efetivo e eficaz de controle da vida coletiva, bem como do exercício da autoridade e do poder.

\begin{abstract}
A potência que unifica os imaginários sociais está baseada na fusão entre a verdade e a normatividade, valores e informações, pelos quais operam justamente a lógica do simbolismo. Desse modo, por meio dos imaginários sociais, a coletividade designa sua identidade, elaborando uma representação de si mesma, marcando a distribuição dos papéis e das posições sociais, bem como expressa e impõe algumas crenças comuns. Assim, é produzida uma representação totalizante da sociedade como uma "ordem", de acordo com a qual cada elemento tem seu lugar, sua identidade e sua razão de ser (BACZKO, 1999, p. 27-28).
\end{abstract}

Sendo, portanto, o conjunto de forças reguladoras da vida coletiva, o imaginário social não indica somente aos indivíduos que eles pertencem a uma mesma sociedade, como também conforma as divisões sociais internas, dando ênfase à figura do "Outro", suas divisões internas e instituições, ou seja, a legitimidade social dos discursos e das práticas.

Inserido no corpo do imaginário social, as representações sociais são transportadas do universo simbólico para o mundo social, atuando nas estratégias de dominação e na determinação dos espaços sociais. "A partir de classificações, determinações, divisões produzidas pelos grupos e classes sociais, criam-se símbolos e figuras que posicionam e condicionam a vida em sociedade" (CHARTIER, 2002, p. 61). Em esteira conexa de pensamento, afirma Chartier (1990, p. 17) “[...] que as ideias sociais não resultam em discursos neutros, mas sim formam práticas e estratégias que impõe uma legitimidade e autoridades que não são, de nenhuma forma, 'naturais' [...]".

"O imaginário social se baseia em simbolismos e, por consequência, a construção de um símbolo apresenta-se fortemente estruturado e dotado de grande estabilidade" (BACZKO, 1999, p. 29), motivo pelo qual a temática da deficiência intelectual também deve ser encarada enquanto um alvo discursivo e institucional inserido no imaginário social, desenvolvido nas sociedades ocidentais modernas. Derivada dessa força que regula a vida coletiva, a 
deficiência intelectual faz parte do imaginário como determinação efetiva e eficaz, possuindo impacto direto no processo educacional.

Nessa linha de pensamento, apresentamos os conceitos de estigma e de normalidade/anormalidade, representações previstas na simbologia do imaginário social enquanto construções de determinação biológica/natural - e não em sua verdadeira roupagem, a de discurso de classificação e divisão social. Para Erving Goffman (1988), o conceito de estigma passa a ser aplicado a diversos contextos sociais. $\mathrm{O}$ autor explica que o estigma foi constituído pelos gregos e representava sinais corpóreos que objetivavam evidenciar algo extraordinário ou negativo sobre a moralidade de quem os possuía. Cortes ou sinais de fogo eram feitos na pele do indivíduo, demonstrando ser ele um criminoso, escravo ou até mesmo traidor.

Alguém com estigma, ou seja, marcado, deveria ser evitado, em especial em locais públicos, pois estava poluído (GOFFMAN, 1988). O autor dispõe que o termo "estigma" se relaciona a um atributo profundamente depreciativo, que pode confirmar a normalidade de alguns e a anormalidade de outros. Goffman (1988, p. 13) ensina que a definição de atributos categorizados enquanto "normais" ou "naturais" assegura a existência de rótulos com a finalidade de criar exigências dotadas de um retrospecto em potencial, uma "identidade social virtual". "Na época contemporânea, o estigma é visto como um sinal claro de uma oculta falha, torpeza social ou iniquidade, gerando no indivíduo um label de aflição ou de vergonha" (GOFFMAN, 1988, p. 12-13).

O estigma deve ser compreendido na relação de quem o elabora, ou seja, na dualidade de quem produz o rótulo e de quem recebe o símbolo depreciativo. A atitude dos "normais" implica um reconhecimento por parte de quem sofre o procedimento de estigmatização. $\mathrm{O}$ indivíduo se vê preso em uma dupla contingência, estar desacreditado - quando sua característica é evidente - ou "desacreditável" - quando sua característica ainda não é conhecida pelos presentes em seu meio (GOFFMAN, 1988). Além disso, em termos de "carreira moral", "[...] o indivíduo estigmatizado aprende e incorpora a visão dos normais, confirmando as crenças nas quais foi moldado e rotulado, não enxergando um estigma pessoal, mas sim uma identidade ou rótulo geral" (GOFFMAN, 1992, p. 41).

Nesse alinhamento, Georges Canguilhem, em especial sobre seu conceito de "normal" e "patológico", esclarece que

[...] a aferição do "normal" - sob o qual as variantes poderiam constituir o conceito de patologia - não pode ser conferido a qualquer organismo vivo senão por intermédio de um ato de valor, uma ação que advém de um campo para além da lógica científica: assim, definir o que é o anormal é mais do que reconhecer a existência de uma norma, deixa de ser uma disposição detectável como um fato e passa a ser uma relação de valor, um apego a uma posição (CANGUILHEM, 2012, p. 23-24).

Somente seria possível compreender o que é normal ou patológico com a compreensão inicial do que é a própria vida - uma polaridade dinâmica, com oscilação de um organismo em momentos distintos, que ocorre durante toda a existência humana. Canguilhem (2012) entende que as relações entre normalidade e anormalidade são moldadas por 
elementos culturais, históricos, geográficos e movimentações próprias de cada época social. As próprias modificações das práticas médicas são geradas pela alteração das estruturas sociais. Logo, seria impossível a medicina ser considerada uma ciência estática, mas compreensível a partir da afirmação de que um fato científico somente ocorre em determinado contexto cultural e histórico próprios.

Essa dualidade, como vimos com Goffman, corresponde a um discurso que não deve ser reduzido em uma antítese lógica, mas como resultado da produção de determinado saber que acompanha o discurso e prática de instituições vigentes no corpo social. A deficiência intelectual, portanto, vista como estigma atribuído ao aluno, é resultado da dualidade com a posição de normalidade reconhecida na linguagem institucional. Em razão da prática reiterada de divulgação desse símbolo de anormalidade, aplicado ao contexto da deficiência intelectual, forma-se e conforma-se um imaginário social que identifica na figura do outro um possível ente de exclusão e determinação das características de normalidade que impregnam as práticas modernas e contemporâneas.

\section{As concepções dos professores sobre a pessoa com deficiência intelectual}

Buscamos compreender a concepção de professores de educação especial sobre a pessoa com deficiência intelectual e a partir dos dados coletados e analisados, identificamos cinco categorias em relação à pessoa com deficiência intelectual. A primeira categoria aponta que a pessoa com deficiência intelectual é concebida como alguém com dificuldade de aprendizagem e/ou raciocínio, com um total de 38 respostas.

Obtivemos respostas como: "Pessoa que tem dificuldades para aprender, entender e realizar atividades que são comuns e rotineiras para a maioria das pessoas [...]"; "Uma pessoa que tem dificuldades de resolver problemas, compreender ideias abstratas"; "são pessoas que possuem dificuldades em realizar atividades, com um atraso no desenvolvimento intelectual para compreender ou resolver problemas [...]". Sobre esse modo de olhar a pessoa com deficiência intelectual, inferimos que pode haver a percepção de que a deficiência intelectual é uma manifestação somente de natureza orgânica e individual, portanto, médica, ligada a uma falta de inteligência, desconsiderando as relações sociais.

Nessa perspectiva, como explica Baczko (1999, p. 28), o imaginário social corresponde a um conjunto de referências simbólicas específicas que toda a coletividade produz, "através do qual ela se percebe, se divide e elabora suas finalidades". Os símbolos sociais designam tanto o objeto como as reações do sujeito em face desse objeto, além de introduzir valores e modelar as condutas, conduzindo os indivíduos a uma ação comum. Produz-se uma representação totalizante da sociedade ou de um fenômeno, "segundo a qual cada elemento tem seu lugar, sua identidade e sua razão de ser”.

Conceber a pessoa com deficiência intelectual como alguém com dificuldade de aprendizagem e/ou de raciocínio tem raízes profundas em meio a esse imaginário social construído ao longo do tempo. A maneira de significar o fenômeno da deficiência intelectual influencia como a pessoa com deficiência intelectual é entendida. Sobre essa questão, Leijoto 
e Kassar (2017, p. 103) analisam que, "desde o século XVII até as primeiras décadas do século $\mathrm{XX}$, a medicina protagonizou as ações referentes ao diagnóstico e ao atendimento de pessoas com deficiências, o que favoreceu o predomínio de uma abordagem organicista na educação dessa população". Os cinco critérios predominantes considerados para a definição dessa condição foram "[...] o caráter de sua constituição, a irreversibilidade da condição, o déficit intelectual, as características do comportamento adaptativo e o período em que aparece o problema".

Constatamos que a relação estabelecida entre a deficiência intelectual e a debilidade do raciocínio deu-se por meio da intervenção da medicina/psiquiatria e da psicologia que a entendiam como um fenômeno somente orgânico que, segundo a perspectiva francesa, poderia ser medido por meio de escalas e modelos estatísticos, em uma relação com a escola que tinha como base, em um determinado momento histórico, a instrução moral dos indivíduos, desacreditando as possibilidades de aprendizado dessas pessoas. É importante ressaltar que, alguns médicos da época, propunham a educação dos "idiotas", apostando em sua educabilidade por meio da medicina moral. Nesse sentido, Pessotti (1984, p. 41), em análise histórica em relação ao Selvagem de Aveyron e aos cuidados médico-pedagógicos de Jean Marc Itard, ao final do século XIX, explica que "a medicina moral era a designação genérica para as atividades da psicologia clínica e da psiquiatria”.

A associação historicamente feita entre a deficiência intelectual e as limitações de caráter cognitivo, outro fator que contribuiu sobremaneira para o enraizamento dessa concepção no imaginário social, refere-se ao uso dos testes de Quociente de Inteligência (QI) para mensurar a "idade mental" daqueles que o realizam. De acordo com Bridi (2013), o primeiro teste de inteligência foi elaborado em 1905, pelos pesquisadores Alfred Binet e Theodore Simon (teste Binet-Simon), os quais responsabilizavam um suposto desenvolvimento inadequado da inteligência entre os alunos que não conseguiam aprender nas escolas públicas de Paris. No entanto, apesar das inúmeras críticas realizadas na época aos testes de QI, ele se consolidou no imaginário coletivo como o mais qualificado instrumento para a medição da inteligência, o que revela a ainda predominante concepção da inteligência como algo inato e estático, tal como concebida desde o século XIX. Sendo assim, a pessoa é colocada como o centro do problema, quando ocorre ênfase em seu desempenho, afirmando-se o atraso cognitivo como uma característica individual, e, portanto, reforçandose uma expectativa em relação ao aprendizado na escola. A permanência dessa perspectiva psicométrica, a qual encontra-se intimamente relacionada à concepção da deficiência intelectual como um fator de ordem biológica e individual, acaba também por não "[...] problematizar a deficiência intelectual como uma produção social, resultado da relação entre biologia e cultura na constituição de sujeitos humanos" (CARNEIRO, 2017, p. 81), excluindo-se, portanto, a dimensão cultural que envolve a construção do próprio conceito de inteligência e deficiência intelectual.

A concepção de deficiência intelectual que predomina no imaginário social dos respondentes contribui para uma "patologização" do sujeito, que é visto como portador de desvio inato ou anormalidade orgânica (CANGUILHEM, 2012, p. 12), fato que colabora para o processo de estigmatização do indivíduo, o qual passa a ser encarado como alguém "não 
completamente humano" (GOFFMAN, 1988, p. 15). Essa perspectiva em nada contribui para o processo de ensino e aprendizagem das pessoas com deficiência intelectual, posto que suprime as expectativas dos professores em relação ao desenvolvimento de seus alunos.

Levando em consideração as expectativas relacionadas à pessoa com deficiência intelectual anteriormente discutidas, elencamos a segunda categoria, que postula a pessoa com deficiência intelectual como alguém que precisa ser cuidado pelo outro, que carece de apoio e/ou atenção. Nessa categoria, houve 31 respostas, indicando: "Pessoa que necessita do outro para se desenvolver"; "São alunos dependentes dos outros até que encontrem a sua autonomia"; "A pessoa com deficiência é aquela que de alguma forma necessita de auxílio em alguma área para um melhor aprendizado"; "Necessita de atenção, independentemente se há muito comprometimento ou não"; "É um indivíduo que passa por um processo que precisa às vezes de muita atenção para que seu aprendizado seja concluído com dedicação, carinho e amor, porque às vezes tem momento difícil e você precisa ter esse cuidado com esse aluno".

Baczko (1999, p. 30) dispõe que o imaginário social produz "um impacto sobre as condutas e atividades individuais e coletivas". O símbolo da deficiência intelectual, encarnado na pessoa, estimula uma ação comum às pessoas, ligada ao cuidado, ao apoio e à atenção. Ao entrar em contato com alguém com deficiência intelectual, dependendo de como a concebemos, pode-se julgar pela aparência e/ou atitudes, enxergando-se uma suposta fragilidade que demandaria cuidado e apoio. Em resposta a essa impressão, decorre uma conduta repleta de compaixão e piedade, típico sentimento dirigido àquele que é visto como incapaz. É necessário dispensar cuidado e atenção a todas as pessoas, desde que isso aconteça sem excesso, retirando a autonomia do sujeito. Atuando numa perspectiva de retirada de autonomia, a tendência é agirmos como se a pessoa fosse incapaz de realizar atividades que podem ser comuns, independentemente de ter ou não deficiência intelectual. Por trás de um olhar generoso, por um lado, pode-se encontrar a subestimação do outro, circunscrevendo as pessoas com deficiência intelectual aos limites da infância, em uma condição de permanente incapacidade e dependência do outro. Por outro lado, a menção ao "cuidado" pode nos revelar uma atitude de índole caridosa do professor em relação ao aluno com deficiência intelectual.

Dessa forma, Goffman (1988, p. 14) assinala que as "atitudes que nós, normais, temos com uma pessoa com um estigma, e os atos que empreendemos em relação a ela são bem conhecidos, na medida em que são as respostas que a ação social benevolente tenta suavizar e melhorar". A atitude benevolente, subentendida nas respostas dos professores, possivelmente se encontra atrelada à tradição brasileira de segregar a educação dirigida às pessoas com deficiência intelectual, bem como atrelada à filantropia das associações particulares (KASSAR, 2011), o que denota desconhecimento tanto da condição da deficiência intelectual como das possibilidades no fazer pedagógico.

Nesse cenário, a terceira categoria nomeia a pessoa com deficiência intelectual como alguém que possui limitações e/ou incapacidades e que, na maioria das vezes, não é capaz de aprender e realizar as mesmas atividades que as outras pessoas. Nessa categoria, há relação da deficiência intelectual com a ausência e a incompletude, que, por sua vez, revelam-se por meio da ideia de que a pessoa com deficiência é alguém que não tem as mesmas 
possibilidades do que os indivíduos considerados "normais": "Uma pessoa com limitação, ou seja, por questões genéticas ou adquirida ao longo da vida"; "Uma pessoa com uma dificuldade ou limitações na percepção do mundo"; "É uma pessoa que tem um retardo e que aprende de forma mais lenta, dentro de suas limitações"; "Pessoa que tem algumas limitações intelectuais"; "Os deficientes intelectuais são aqueles que, por algum motivo, possuem uma incapacidade de nível funcional que acarretará em um desempenho abaixo do esperado". Dessa maneira, sobre aqueles que expressam o signo da "anormalidade" são atribuídos alguns valores, a depender da natureza de sua diferença.

É importante ainda ressaltar que, nessa categoria, três docentes responderam: "É uma criança como outra, porém com suas limitações, mas que são capazes de realizar atividades escolar e pessoal como a outra"; "São alunos (pessoas) que têm suas limitações, mas são pessoas com capacidade para aprender"; "A pessoa com deficiência intelectual é capaz de aprender respeitando suas limitações, irá demandar metodologias diversas, a fim de que o aluno se aproprie destas". Essas falas se misturam a uma possibilidade do fazer pedagógico, daí a importância da formação continuada de professores, pelo fato de que, no caso da formação de professores em educação especial e para a inclusão escolar, ela não tem se configurado de maneira simples, tanto pela construção das práticas pedagógicas historicamente produzidas, quanto pela forma como essa formação vem se desenhando (CAETANO, 2009).

Conjuntamente à análise da primeira e da segunda categorias, observamos uma relação complementar, na medida em que, para os respondentes, por um "déficit cognitivo", a pessoa com deficiência intelectual, apresenta incapacidades que a impedem de progredir intelectualmente. Transportando essa análise ao âmbito escolar, pode-se inferir que professores de educação especial têm baixas expectativas sobre o desenvolvimento e a aprendizagem de seus alunos, cujos "limites" parecem representar um obstáculo intransponível à sua aprendizagem. Inclusive, em pesquisa realizada sobre a deficiência intelectual na concepção de educadores da educação especial, Rossato e Leonardo (2011, p. 80-81) expõem que o resultado do estudo revelou a "[...] falta de perspectiva de desenvolvimento em relação às pessoas com deficiência intelectual, estando suas possibilidades de aprendizado cingidas ao aspecto orgânico [...]". Em um dos relatos obtidos de um dos professores de educação especial, percebe-se a importância dada ao resultado "mínimo" alcançado com seus alunos. Segundo as autoras, "quando algo de "bom" se conquista com esse aluno, por "mínimo" que seja, ultrapassa-se a linha de superação" (ROSSATO; LEONARDO, 2011, p. 81, grifos do original). Consequentemente, o estigma lançado sobre a pessoa com deficiência intelectual pode influenciar que o professor desconsidere as potencialidades daquele aluno, considerando como improdutiva qualquer tentativa de ensiná-lo.

A partir da análise dos questionários, constatamos que há uma tendência no que diz respeito à concepção dos professores de educação especial em relação aos seus alunos com deficiência intelectual. Schütz (2006), De Vitta, De Vitta e Monteiro (2010), Raymundo (2010), Teles (2010), Valentim e Oliveira (2013) e Camizão (2016) concluíram que grande 
parte dos professores considera que a deficiência intelectual impõe limites cognitivos àqueles que vivem essa condição.

Entendemos ser fundamental que, ao desenvolver suas atividades com o aluno com deficiência intelectual, o professor foque nas potencialidades do aluno, e não nas supostas "limitações" que dificultam sua aprendizagem; isso porque, tal como qualquer outro ser humano, a pessoa com deficiência também pode aprender. As supostas "limitações" não deveriam ser empregadas como desculpas para não desenvolver um trabalho com o mesmo compromisso como aquele realizado com os alunos sem deficiência. Concordamos com Melo e Mafezoni (2019) que a escolarização de pessoas com deficiência deve se realizar a partir dos mesmos parâmetros e objetivos daquela destinada às pessoas sem deficiência. A diferença no encaminhamento das ações e da prática é o trabalho com oferecimento de técnicas, instrumentos e métodos didático-pedagógicos.

$\mathrm{Na}$ continuação da discussão, construímos a quarta categoria, que aponta a compreensão da pessoa com deficiência intelectual como alguém que possui seu próprio tempo e tem formas diferentes de aprender. Ressaltamos algumas respostas dos professores: "Uma pessoa que tem capacidade, dentro do seu tempo, de viver e se integrar em sociedade"; "é uma pessoa capaz e que é um ser humano único e que no seu tempo vai avançar"; "Esse aluno aprende no tempo dele, por isso temos que ter atividades diferenciadas para incentiválos com o aprendizado"; "Uma pessoa que tem condições de aprender, porém de forma diferente e mais demorada, e alvo de muito carinho e amor"; "Forma diferente que as pessoas têm de interpretar o que está acontecendo ao seu redor".

Canguilhem (2012, p. 48) explica que o termo "normal" sempre foi atribuído àquilo "que não se inclina nem para a esquerda nem para a direita", conservando-se "em um justo meio-termo; daí derivam dois sentidos: é normal aquilo que é como deve ser; e é normal [...] o que se encontra na maior parte dos casos de uma espécie determinada ou o que constitui a média ou o módulo de uma característica mensurável". Para o autor, a lógica do discurso da normalidade advém de estabelecimento de parâmetros por parte das instituições que ditam o saber e, portanto, inserem signos de padronização. A existência do normal não é algo concreto, mas um elemento travestido de cientificidade, ou seja, uma afirmação arbitrária, que gera uma normatividade ao contexto social. Logo, os métodos científicos estabelecidos pelas áreas biomédicas ditam, há tempos, uma distinção entre normalidades e patologias, desdobrando na compreensão do que viria a ser um anormal. Daí a manifestação na categoria em comento, posto que Canguilhem (2012) já havia destacado que os objetos de medida da fisiologia tributam a patologia em sede de identificação, ou seja, não haveria uma "ontologia" da anormalidade, mas sim um rótulo a ser empregado.

A categoria ora analisada acerca do conceito de deficiência intelectual ajusta-se àquilo que, historicamente, tem sido considerado "anormal": uma inclinação que foge do padrão de normalidade, conservando-se fora do justo meio-termo; como a maioria das pessoas considera que a pessoa com deficiência intelectual foge da retidão na qual encontram-se as pessoas consideradas normais, daí dizer que a pessoa com deficiência intelectual tem seu próprio tempo ou aprende de maneiras diversas, estando fora do padrão, ou seja, daquilo "que é como deve ser". 
As respostas contidas nessa categoria, de certa forma, representam um avanço, se comparadas às respostas que simplesmente compreendem a pessoa com deficiência intelectual como alguém "com dificuldade de aprendizagem e/ou de raciocínio" ou como alguém "que possui limitações e/ou incapacidades". Entender a pessoa com deficiência intelectual como alguém que "tem seu próprio tempo e/ou formas de aprender diferentes", indica ao menos que o respondente enxerga essa pessoa como um ser humano capaz de se desenvolver, retirando-o dos limites da "não aprendizagem", desde que não esteja embutida nas afirmações a possibilidade de deixar o processo de ensino-aprendizagem sem planejamento e sem direcionamento. Se esse for o caso, voltamos a um círculo vicioso de que nada é preciso ensinar à pessoa com deficiência intelectual. Nesse sentido, a singularidade do aluno com deficiência não estaria contida na sua incapacidade cognitiva, mas no método a ser empregado pelo docente em seu processo de ensino e aprendizado.

A título de finalização, a última categoria compreende a pessoa com deficiência intelectual como alguém com potencialidades e/ou como sujeito de direitos e deveres. Nesse sentido, percebemos um movimento em relação a um alinhamento à Educação Inclusiva, resgatando a pessoa com deficiência intelectual da dimensão da dificuldade de aprendizagem, dos limites, da dependência do outro, mas enxergando-a como cidadã em toda sua complexidade, detentora de potencialidades, bem como de direitos e de deveres. Esse certamente é um reflexo dos recentes esforços pela promoção da Educação Inclusiva, a qual busca oferecer uma educação que não discrimine o indivíduo em detrimento de sua condição física e intelectual.

Desde que o Brasil se tornou signatário de Convenções e Declarações internacionais na década de 1990, coube ao país o dever de assegurar a universalização do direito à educação em movimento a uma Educação Inclusiva. Anteriormente a esse movimento inclusivo, o que vigorou durante muitas décadas, no Brasil, foi uma separação entre o atendimento educacional direcionado às pessoas com deficiência e aquele oferecido às pessoas ditas "normais". Essa separação acarretou um sistema paralelo de ensino, "[...] de modo que o atendimento de alunos com deficiência ocorreu de modo incisivo em locais separados dos outros alunos [...]", revelando-se como uma preferência, e não exceção na história da educação brasileira (KASSAR, 2011, p. 62).

Como esse paradigma segregacionista passou a ser questionado apenas ao término do século XX, é compreensível que a maioria dos professores de educação especial ainda esteja submetida ao imaginário social que enaltece as supostas ausências, limitações e dificuldades atribuídas às pessoas com deficiência intelectual. No entanto, a tendência que parece emergir indica a construção de um pensamento voltado ao enaltecimento de direitos, deveres e potencialidades desse público da educação especial. Essa tendência, ao longo das próximas décadas, certamente superará o paradigma segregacionista e estigmatizante, imposto sobre as pessoas com deficiência intelectual. 


\section{Considerações finais}

Por meio do presente artigo, apresentamos e discutimos as concepções que professores de educação especial de um município da RMGV/ES compartilham acerca da pessoa com deficiência intelectual. Entendemos que as confusões em torno do conceito de deficiência intelectual; atrelado à pessoa, influencia as ações pedagógicas, prejudicando ou contribuindo com o processo de ensino e aprendizado do aluno.

O predomínio de concepções estigmatizantes, conjuntamente com as particularidades da realidade local, contribuem para a construção de uma postura pedagógica que compreende o aluno (pessoa) com deficiência intelectual como um indivíduo delimitado pela "não aprendizagem", sobre o qual há pouca ou não há expectativa. O prejuízo oriundo dessas concepções repousa sobre a naturalização de uma cultura escolar que não se empenha em contribuir para o desenvolvimento do aluno com deficiência intelectual, constituindo um mero cumprimento estéril do que dispõe a legislação educacional.

Ainda que a maioria das respostas se alinhe às concepções estigmatizantes, observa-se a emergência de um novo paradigma, voltado à compreensão da pessoa com deficiência intelectual como um sujeito de direitos e potencialidades. Esse novo imaginário social, verdadeiramente alinhado aos desígnios da Educação Inclusiva, representa uma tendência crescente não apenas entre aqueles que trabalham com o público-alvo da educação especial, mas também entre todos os sujeitos escolares.

Para que essa tendência se consolide, uma das possibilidades é a de que a formação inicial e continuada dos professores de educação especial, que sustentam a Educação Inclusiva, se libertem de um imaginário social, assim como do estigma e a sua relação entre o normal e o patológico, nocivo às práticas pedagógicas. O imaginário social do século XXI carece de desvincular-se das concepções organicistas do século passado, possibilitando compreender a deficiência intelectual por meio de um viés histórico-cultural, sem reduzir as suas especificidades, segundo o qual a pessoa com deficiência é considerada um sujeito pleno para o desenvolvimento e a aprendizagem.

\section{Referências}

BACZKO, Bronislaw. Los imaginarios sociales. Memorias y esperanzas colectivas. Buenos Aires: Nueva Visión, 1999.

BARDIN, Laurence. Análise de conteúdo. São Paulo: Edições 70, 1988.

BRIDI, Fabiane Romano de Souza. Deficiência mental: possíveis leituras a partir dos manuais diagnósticos. In: REUNIÃO NACIONAL DA ANPEd: SISTEMA NACIONAL DE EDUCAÇÃO E PARTICIPAÇÃO POPULAR: DESAFIOS PARA AS POLÍTICAS EDUCACIONAIS, 36., 2013, Goiânia. Anais... Goiânia: UFG, 2013. 
CAETANO, Andressa Mafezoni. A formação inicial de professores na perspectiva da inclusão escolar de alunos com deficiência: o curso de Pedagogia da Universidade Federal do Espírito Santo. 2009. 238 f. Tese (Doutorado em Educação) - Programa de PósGraduação em Educação, Universidade Federal do Espírito Santo, Vitória, 2009.

CAMIZ̃̃O, Amanda Costa. Conhecimentos, concepções e prática de professores de educação especial: o modelo médico-psicológico ainda vigora? 2016. 180 f. Dissertação (Mestrado em Educação) - Programa de Pós-Graduação em Educação, Universidade Federal do Espírito Santo, Vitória, 2016.

CANGUILHEM, Georges. O normal e o patológico. Tradução de Maria Thereza Redig de Carvalho Barrocas. Rio de Janeiro: Forense Universitária, 2012.

CARNEIRO, Maria Sylvia Cardoso. Contribuições da abordagem histórico-cultural para a compreensão da deficiência intelectual como produção social. In: CAIADO, Kátia Regina Moreno; BAPTISTA, Cláudio Roberto; JESUS, Denise Meyrelles de (org.). Deficiência mental e deficiência intelectual em debate. Uberlândia: Navegando Publicações, 2017. p. 79-99.

CHARTIER, Roger. Introdução. Por uma sociologia histórica das práticas culturais. In: CHARTIER, Roger. A história cultural entre práticas e representações. Tradução de Maria Manuela Galhardo. Rio de Janeiro: Bertrand Brasil, 1990. p. 13-28.

CHARTIER, Roger. O mundo como representação. In: CHARTIER, Roger. À beira da falésia: a história entre incertezas e inquietude. Tradução de Patrícia Chittoni Ramos. Porto Alegre: Ed. Universidade/UFRGS, 2002. p. 61-80.

DE VITTA, Fabiana Cristina Frigieri; DE VITTA, Alberto; MONTEIRO, Alexandra. Percepção de professores de educação infantil sobre a inclusão da criança com deficiência. Revista Brasileira de Educação Especial. Marília, v. 16, n. 3, p. 415-428, dez. 2010. https://doi.org/10.1590/S1413-65382010000300007

GOFFMAN, Erving. Estigma: notas sobre a manipulação da identidade deteriorada. 4. ed. Rio de Janeiro: Guanabara, 1988.

GOFFMAN, Erving. Manicômios, prisões e conventos. Tradução de Dante Moreira Leite. São Paulo: Editora Perspectiva, 1992.

KASSAR, Mônica de Carvalho Magalhães. Educação especial na perspectiva da educação inclusiva: desafios da implantação de uma política nacional. Educar em Revista. Curitiba, n. 41, p. 61-79, jul./set. 2011. https://doi.org/10.1590/S0104-40602011000300005

LAVILLE, Christian; DIONNE, Jean. A construção do saber: manual de metodologia da pesquisa em ciências humanas. Tradução de Heloísa Monteiro e Francisco Settineri. Porto Alegre: Artmed; Belo Horizonte: Editora UFMG, 1999.

LEIJOTO, Camila Pereira; KASSAR, Mônica de Carvalho Magalhães. Reflexões acerca do conceito de deficiência intelectual/mental para delineamento da população escolar brasileira para registro no censo escolar. In: CAIADO, Kátia Regina Moreno; BAPTISTA, Cláudio 
Roberto; JESUS, Denise Meyrelles de (org.). Deficiência mental e deficiência intelectual em debate. Uberlândia: Navegando Publicações, 2017. p. 101-122.

MELO, Douglas Christian Ferrari de; MAFEZONI, Andressa Caetano. O direito de aprender e os alunos público-alvo da especial. Revista Educação em Debate. Fortaleza, v. 41, n. 78, p. 101-115, jan/abr. 2019. http://dx.doi.org/10.24882/eemd.v41i78.831

MENDES, Encéia Gonçalves. A política de educação inclusiva e o futuro das instituições especializadas no Brasil. Education Policy Analysis Archives. Arizona, v. 27, n. 22, mar. 2019. http://dx.doi.org/10.14507/epaa.27.3167

MOREIRA, Herivelto; CALEFFE, Luiz Gonzaga. Metodologia da pesquisa para o professor pesquisador. 2. ed. Rio de Janeiro: Lamparina, 2008.

PESSOTTI, Isaías. Deficiência Mental: da superstição à ciência. São Paulo, EDUSP: 1984.

RAYMUNDO, Davidson Nunes. Indícios da aprendizagem da criança com deficiência intelectual: contribuições da abordagem histórico-cultural e a formação de educadores de educação infantil. 2010. 208 f. Dissertação (Mestrado em Educação) - Programa de PósGraduação em Educação, Universidade Federal do Espírito Santo, Vitória, 2010.

ROSSATO, Solange Pereira Marques; LEONARDO, Nilza Sanches Tessaro. A deficiência intelectual na concepção de educadores da educação especial: contribuições da psicologia histórico cultural. Revista Brasileira de Educação Especial. Marília, v. 17, n. 1, p. 71-86, jan./abr. 2011. https://doi.org/10.1590/S1413-65382011000100006

SCHÜTZ, Maria Rosa Rocha dos Santos. Avaliação escolar como instrumento de mediação da aprendizagem na educação inclusiva: desafios no cotidiano escolar. 2006. 132 f. Dissertação (Mestrado em Educação) - Programa de Mestrado Acadêmico em Educação, Universidade do Vale do Itajaí, Itajaí, 2006.

TELES, Stela Martins. O professor no processo de inclusão de alunos com deficiência intelectual: um estudo sobre os significados construídos no fazer pedagógico. 2010. $130 \mathrm{f}$. Dissertação (Mestrado em Processos de Desenvolvimento Humano e Saúde) - Instituto de Psicologia, Universidade de Brasília, Brasília, 2010.

VALENTIM. Fernanda Oscar Dourado; OLIVEIRA, Anna Augusta Sampaio de. Avaliação da aprendizagem e deficiência intelectual na perspectiva de professores do ensino comum.

Revista Diálogo Educacional. Curitiba, v. 13, n. 40, p. 851-871, set./dez. 2013. http://dx.doi.org/10.7213/dialogo.educ.13.040.DS02

Checagem Antiplágio

Crossref

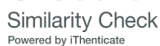

Distribuído sobre

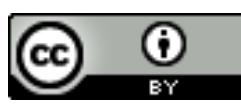

